\title{
A note on natural population levels of Phthirapteran species on sheep at district Rampur (U. P.), India
}

\author{
Archna Rashmi and A. K. Saxena* \\ Department of Zoology, Govt. Raza P.G. College, Rampur -244901 (U.P.), INDIA \\ *Corresponding author. E-mail: akscsir@rediffmail.com
}

Received: November 29, 2015; Revised received: June 22, 2016; Accepted: November 1, 2016

\begin{abstract}
A look on the available literature indicated that population characteristics of Phthiraptera on Indian sheep deserved investigation. Two hundred sheep were sampled to reveal the population levels of phthirapteran species on sheep in the district Rampur (U.P.). Three phthirapteran species were recovered (Bovicola ovis Schrank, the face louse, Linognathus ovillus Neumann and the foot louse of sheep, Linognathus pedalis Osborn). The prevalence to Phthiraptera on sheep was $26.5 \%,(n=200)$ during 2007. The difference in the prevalence of Phthiraptera on two sexes of sheep was not found significant at $5 \%$ level. Likewise, the difference in the prevalence of phthirapteran species on young, adult and older sheep was also insignificant at $5 \%$ level. The prevalence and intensity of infestation of Phthiraptera were found significantly correlated (at $5 \%$ level) to mean monthly temperature. The correlation between prevalence and relative humidity was not found significant at $5 \%$ level. The present report provides first information on the population characteristics of phthirapteran ectoparasites infesting Indian sheep.
\end{abstract}

Keywords: Bovicola ovis, Lice, Linognathus ovillus, Linognathus pedalis, Phthiraptera

\section{INTRODUCTION}

Ectoparasitic insects infesting sheep have been discussed by George et al. (1992), Yanan and Mohammed (2001) and Gabaj et al. (2008). Workers like Ward and Armstrong (1999), Bisdorff et al. (2006), Yacob et al., (2008) and Changbunjong et al. (2009) have noted the prevalence of sheep lice in different parts of the world. Surprisingly, there is no report on the prevalence of Phthiraptera on Indian sheep. Distribution of ectoparasites on sheep has been further discussed by James and Moon (1999). The kind of skin injuries caused by sheep ectoparasites and the economic impact of parasitism have been indicated by several workers (Liebisch, 1988; James et al., 1993; Rodostits et al., 1994; Bayou, 1998; Ward \& Armstrong, 2000; Chalachew, 2001; Kirst et al., 2002; Kumsa et al., 2012, Kufman et al., 2012, Amare et al., 2013 and Bedada et $a l ., 2015)$. An scrutiny of literature revealed that studies on the population of Phthiraptera on Indian sheep has escaped the attention of workers. The present paper deals with population characteristics of three phthirapteran species infesting sheep in districts Rampur (India).

\section{MATERIALS AND METHODS}

AS many 200 sheep (20 young, 70 adults and 110 older) were surveyed during January to December, 2007 in five different localities of district Rampur. Sheep were examined by hair parting method given by
Lewis et al. (1967) at 20 anatomical sites (measuring 1 square inch by placing the thick wire molded in square shape) with the help of magnifying lens fitted with light. Lice load from different sites of body were handpicked and transferred to glass tubes containing $70 \%$ ethyl alcohol (using separate vial for each host). Each tube contained information regarding host sex, stage and locality. Later, lice were separated species wise, sex wise and stage wise under Stereo zoom trinocular microscope. Prevalence was calculated by dividing total number of infested hosts $\mathrm{x} 100$ by the total number of examined hosts. Intensity of infestation was computed by dividing total numbers of lice recovered by total number of infested hosts. Likewise, sample mean abundance was calculated by dividing total number of lice recovered by total number of examined hosts. Significance of difference in prevalence was tested by using $X^{2}$. Degree of correlation between mean monthly prevalence and mean monthly value of two eco-factors (mean monthly temperature and mean monthly RH) by deriving the value of Karl Pearson's coefficient of correlation.

\section{RESULTS AND DISCUSSION}

The sheep biting louse, Bovicola ovis (Schrank), face louse, Linognathus ovillus (Neumann), and foot louse Linognathus pedalis (Osborn) were recorded from sheep in five localities (City proper, Swar, Tanda, Bilaspur and Milak) in the district Rampur during January to December, 2007 while observing the population 


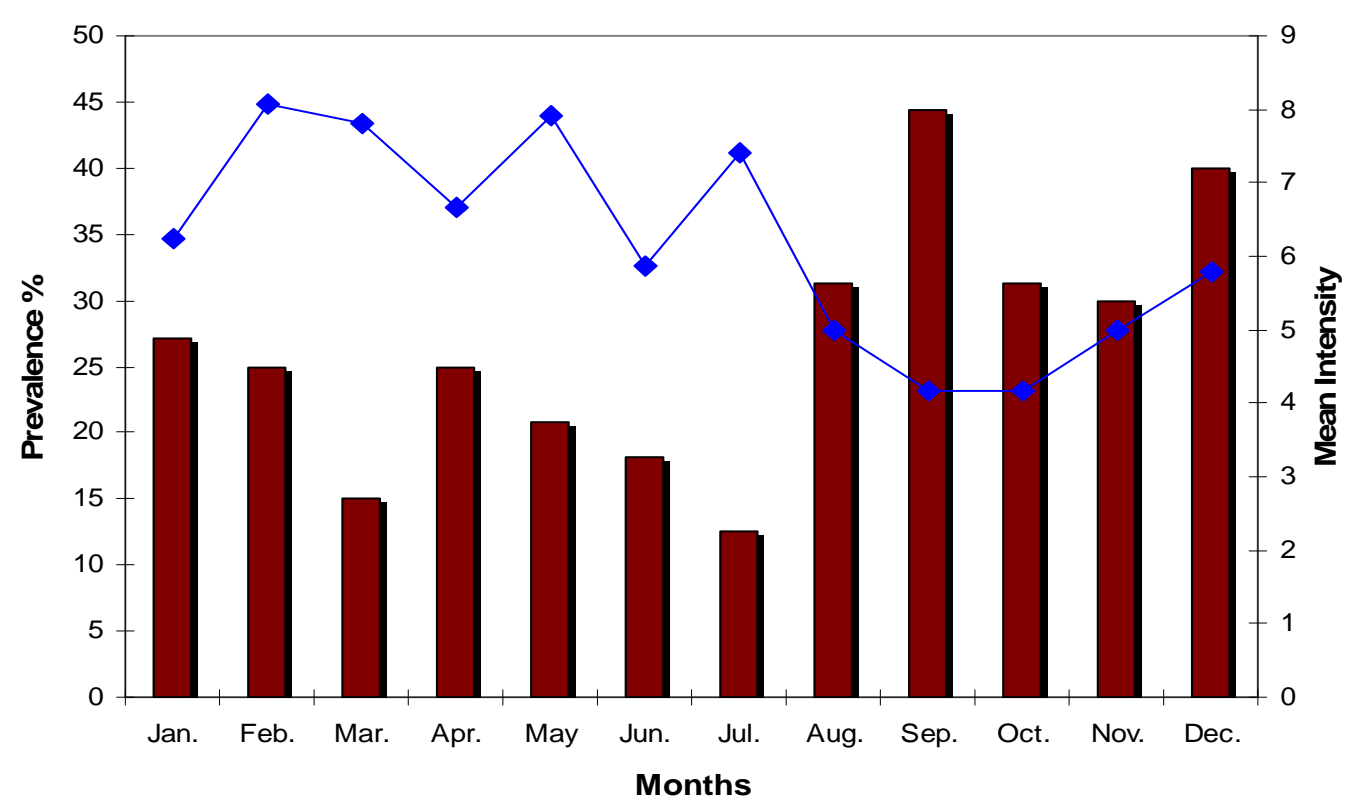

Fig. 1. Showing the prevalence and intensity of infestation (based on mean of numbers counted phthirapteran on 200 sheep during different months of the year 2007, in the district Rampur (U.P.).

on 20 sites per host) of

characteristics of sheep lice. Eighty sheep were males and 120 females. Prevalence of Phthiraptera on male and female remained $28.7 \%$ and $25 \%$, respectively $\left(\mathrm{X}^{2}\right.$ $=0.34, \mathrm{P}<0.05$, insignificant). Furthermore, out of the 200 sheep examined, 20 were young, 70 adults and remaining 110 older ones. The prevalence of sheep lice on young adult and older sheep remained 30\%, $22.8 \%$ and $28.18 \%$, respectively. Statistical analysis analysis showed that differences in the prevalence rate in three groups were insignificant $\left(\mathrm{X}^{2}=0.811, \mathrm{P}<0.05\right)$. The overall prevalence of Phthiraptera on sheep was $26.5 \%$ $(n=200)$. Maximum percentage of infested sheep bore single species infestation (62.2\%). Double species infestation was present upon $20.7 \%$ hosts while $16.9 \%$ sheep carried triple species infestation.

Linognathus ovillus: During the present study face louse, L.ovillus was mostly found confined to face and the flecce which border the face. The prevalence of L.ovillus on sheep was $7.0 \%(\mathrm{n}=200)$. A total of 1327 lice (all the stages) were collected from the infested sheep (mean intensity 5.8 per square inch). The sample mean abundance was 0.40 per square inch (range, 65$138, \mathrm{n}=200$ ) (based on 20 sites). For observing the population structure at different levels of infestation, entire data was divided into four categories. Two sheep carried 65-75 (mean of lice collected from all the 20 sites) lice (mean number, 66.0; 10.5M, 14.5F, 41.0N; M: F = 1:1.3; A: $\mathrm{N}=1: 1.6)$. Five sheep had 76-86 specimens of L.ovillus (mean number, 81.40; 10.8M, 16.8F, 53.8N; M: $\mathrm{F}=1: 1.5, \mathrm{~A}: \mathrm{N}=1: 1.9$ ). As many as, two sheep were found infested with 87-97 lice (mean number, 93.5; 10.5M, 15.5F, 67.5N; M: F = 1:1.4; $\mathrm{A}: \mathrm{N}=1: 1.25)$. More than 97 lice were present upon five sheep (mean number,
120.2; 13.0M, 19.2F, 88.0N; M: F = 1:1.4; A: $\mathrm{N}=1: 1.3$ ). In overall population composition, the mean number remained $94.8(11.5 \mathrm{M}, 17.14 \mathrm{~F}, 66.14 \mathrm{~N})$. The overall ratio of male and female, adult nymph and three nymphal instars were found to be 1:2,1:2.3 and 1: 1.4: 1.6, respectively.

Linognathus pedalis: Most of the population of L.pedalis was confined to hind legs and fore legs. Few lice occurred on back also. Prevalence of L.pedalis on sheep was $11.5 \%(n=200)$. As many as, 1633 lice (all the stages) were collected from the infested sheep (mean intensity, 2.8 per square inch). The value of sample mean abundance was 0.33 per square inch. For observing the population structure at different levels of infestation, entire data was divided into four categories. Two sheep carried 43-53 (total number of lice counted from all the 20 sites) specimens of L.pedalis (mean number, 46.0; 7.0M, 10.5F, 28.5N; M: F = 1:1.5; A: $N=1: 1.6$ ). Four sheep carried 54-64 lice (mean number, 60.3; 9.3M, 13.0F, 38.0N; M: F = 1:1.4; $\mathrm{A}: \mathrm{N}=$ $1: 1.7)$. Maximum number of sheep (10) bore $65-75$ specimens of L.pedalis (mean number, 68.6; 9.6M, 13.6F, 45.4N; M: F = 1:1.5; A: N = 1:1.9). Seven sheep were infested with more than 75 lice (mean number, 87.7; 9.2M, 16.4F, 62.0N; M: F = 1:1.7; A: $\mathrm{N}=1: 2.4)$. The data indicates mean number remained $71.0(9.2 \mathrm{M}, 14.1 \mathrm{~F}$, $47.7 \mathrm{~N} ; \mathrm{M}: \mathrm{F}=1: 1.5 ; \mathrm{A}: \mathrm{N}=1: 1.2)$. The overall ratios of three nymphal instars were found to be 1: 1.3: 1.6.

Bovicola ovis: In the present study B.ovis exhibited wide spread distribution on the body of sheep and was recovered from back, nape, abdomen and neck regions of the body of host . The prevalence of B.ovis on sheep was found $22.5 \%,(n=45)$. As many as, 3226 lice (all the stage) were collected from the infested sheep 
(mean intensity, 3.5 per square inch). The value of sample mean abundance remained 0.80 per square inch (based on 20 sites) (range, 15-131, $\mathrm{n}=200$ ). For the sake of description, entire data was divided into four classes. Six sheep carried 15-40 lice (mean number, 29.33; 4.16M, 6.5F, 18.66N; M: F = 1:1.5; A: $\mathrm{N}=$ $1: 1.7)$. Maximum number of sheep (23) were infested with 41-80 specimens of B.ovis (mean number, 61.3, 8.3M, 13.1F, 39.7N; M:F = 1:1.5; A:N = 1:1.8). Thirteen sheep carried 81-120 lice (mean number, 96.9; $11.1 \mathrm{M}, 17.0 \mathrm{~F}, 68.7 \mathrm{~N}$; $\mathrm{M}: \mathrm{F}=1: 1.5 ; \mathrm{A}: \mathrm{N}=1: 2.4)$. Only three sheep had more than 120 lice (mean number, 127.0; 13.0M, 19.3F, 94.6N; M: F = 1:1.4; A: $\mathrm{N}=$ $1: 2.9)$. In overall population composition, mean number remained $71.7(8.9 \mathrm{M}, 13.7 \mathrm{~F}, 49.0 \mathrm{~N} ; \mathrm{M}: \mathrm{F}=1: 1.5$; A: $\mathrm{N}=1: 2.1)$. The overall ratio of three nymphal instars was 1: 1.2: 1.6.

Seasonal variation: During the present study, prevalence of Phthiraptera on sheep remained $27.2 \%$, in January, became $(25 \%)$ in February, decreased in March (15\%), again rose in April (25\%), exhibited gradual decline in three subsequent months $(20.8 \%$, $18.1 \%$ and $12.5 \%$, respectively) (Fig. 1). It increased in August (31.2\%), reached maximum (44.4\%) in September, declined, in October $(31.2 \%)$, remained nearly at same level in November $(30 \%)$ and again increased in December (40\%) (Fig. 1). Likewise, mean intensity of infestation was 6.2 (per square inch) in January, 8.1 in February, 7.8 in March, 6.7 in April and 7.9 in May. The intensity became slightly reduced in June (5.9). It increased in July (7.4) and remained low during four subsequent months (August 4.9, September 4.2, October 4.2 and November 4.9, respectively). It exhibited slightly increase in December (5.7).

The correlation between mean monthly prevalence and mean monthly temperature $(r=0.62)$ was found significant at $5 \%$ level. Likewise, correlation between mean monthly lice index (mean numbers recorded per square inch at 20 anatomical sites) and the mean monthly temperature $(\mathrm{r}=-0.58)$ was also significant at $5 \%$ level. The correlation between mean monthly prevalence and mean monthly relative humidity was not significant $(\mathrm{r}=0.53)$ but the correlation between mean monthly intensity and relative humidity was found significant $(r=0.83)$ at $5 \%$ level.

Survey of literature indicates that there is no report on the prevalence of Phthiraptera on domestic sheep of India. The prevalence and intensity of phthirapteran ectoparasites exhibits considerable variation in different parts of the world (Bisdorff et al., 2006; Yacob et al. 2008; Changbunjong et al., 2009; Kumsa et al., 2012; Kufman et al., 2012; Amare et al., 2013; Bedada et al., 2015). During present study the overall prevalence of Phthiraptera on sheep was recorded as $26.5 \%$ in the district Rampur, during 2007. B.ovis was the most prevalent sheep lice, followed by sheep face louse L.ovillus. The sheep foot louse, L.pedalis re- mained the least prevalent species. Furthermore, there was no significant difference in the prevalence of lice on two sexes of sheep (at 5\% level). Likewise, differences in the prevalence of Phthiraptera on younger, adult and older sheep also remained insignificant at 5\% level. On the basis of grading system adopted during present study the mean intensity of three phthirapteran species remained 194.7 (based on 20 sites). Furthermore, the prevalence of Phthiraptera on sheep varied from $12.5 \%-44.4 \%$, from January to December in the year 2007. The prevalence was above, $25 \%$ from August to February. It remained below $21 \%$ in remaining months (March to July, except April). However, the mean intensity of infestation appeared to be higher during winter months in contrast summer months. Mammalian lice are known to exhibit maxima during winter months. As far as, population composition is concerned, as per expectation, females outnumbered the males in natural population and nymphal population dominated over adults in case of all three species. Present report furnishes first information on the population levels of phthirapteran ectoparasites on sheep of an Indian locality.

\section{Conclusion}

Present report furnishes first information on the population levels of three phthirapteran species on two hundred Indian sheep. The prevalence of Phthiraptera was $26.5 \%$. The mean intensity of infestation was 194.7 (based on 20 sites measuring one square inch). Host sex or stage related differences in the prevalence and intensity of phthirapterans were not significant at 5\% level. The prevalence intensity of infestation was found significantly correlated to mean monthly temperature.

\section{ACKNOWLEDGEMENTS}

The authors are thankful to the Principal, Govt. Raza P. G. College, and Rampur, for laboratory facilities, and to the UGC, New Delhi, India for providing financial support to Archna Rashmi, in the form Rajeev Gandhi National Fellowship.

\section{REFERENCES}

Amare, S., Asfaw, Y. and Hailu, Y. (2013). Ectoparasites of sheep and goat north west Amhara regional state Ethiopia. Ethiopian Veterinary Journal, 17: 55-62

Bayou, K. (1998). Overview of sheep and goat skin disease, treatment trial for improved quality of hides and skins. Proc. FALMOA Addis Ethopia, 13-20

Bedada, H., Terefe, G. and Tolossa, Y.H. (2015). Current status of ectoparasites in sheep and management practices against the problem in ectoparasites controlled and uncontrolled areas of arsi zone in Oromia region, Ethiopia. J.Vet.Sci. Technol., S10: 002. doi:10. 4172/2157-7579. S10-002

Bisdorff, B., Wall, R. and Milnes, A. (2006). Prevalence and regional distribution of scab, lice and blowfly strike in Great Britain. The Vet. Record, 158: 749-752 
Chalachew, N. (2001). Study on skin disease of cattle, sheep and goats in Walaita Saddo Southern Ethiopia. DVM thesis, Faculty of Vetnary medicine, Addis Ababa University.

Changbunjong, T., Buddhirongawatr, R., Suwanpakdee, S., Siengsanan, J., Yongyuttawichai, P., et al. (2009). A survey of ectoparasitic arthropods on domestic animals in Tak Province, Thailand. Southeast Asian J. Trop. Med. Public Health, 40: 435-442

Gabaj, M.M., Beesley, W.N. and Awan, M.A. (2008). Lice of farm animals in Libya. Med. Vet. Entomol., 7: 138-40

George, J.B., Otobo, S., Ogunleye, J. and Adediminiyi, B. (1992). Louse and mite infestation in domestic animals in northern Nigeria. Trop. Anim. Hlth., Prod., 24: 12124

James, P.J., Saunders, P.E., Cockrun, K.S. and Munro, K.J. (1993). Resistance to synthetic pyrethroids in South Australian population of sheep lice. Aust. Vet. J., 70(3): 105-8

James, P.J., and Moon, R. (1999). Spatial distribution and spread of sheep biting louse Bovicola ovis from point infestation. Vet. Parasitol., 81:323-339

Kirst, H.A., Creemer, L.C., Naylor, S.A., Pugh, P.T., Synder, D.E., Wikle, J.R., Loue, L.B., Rothwell, J.T., Sparks, T.C. and Worden, T.V. (2002). Evaluation and development of spinosyns to control ectoparasites on cattle and sheep. Curr. Top. Med. Chem., 2(7): 675-99

Kufman, P.E., Koehler, P.G. and Butler, J.F. (2012). External parasites of sheep and goats. University of Florida. IFSA extension. pp. 168-200
Kumsa, B., Beyecha, K. and Geloye, M. (2012). Ectoparasites of sheep in three agroecological zones in central Oromia, Ethiopia. Onderstepoort J. Vet. Res., 79: E1- 7.

Lewis, L.F., Christenson, D.M. and Eddy, G.W. (1967). Rearing of long-nosed cattle louse and cattle biting louse on host animals in Oregon. J. Econ. Entomol., 60: 755-757

Liebisch, A. (1988). Study on the duration of activity of cytluthrin $1 \%$ pour- on in sheep infested with sheep Keds (Melophagus ovinus). Vet. Med. Review., 59: 127132

Rodostits, O.M., Blood, D.C. and Gray, C.C. (1994). Vetrinary Medicine: A text book of the diseases of cattle, sheep, pig, goats and horses. 8th Edition, Bailliere Tindall, 1578

Ward, M.P. and Armstrong, R.T.F. (1999). Prevalence and clustering of louse infestation in Queensland sheep flock. Vet. Parasiltol., 82(3). 243-250

Ward, M.P. and Armstrong, R.T.F. (2000). Inspection of wool lots at dales as a diagnostic test for louse infestation. Vet. Parasitol., 90: 119-128

Yanan, E.G. and Mohammed, A.A. (2001). The incidence of lousiness in sheep with in Sokoto metropolis. Proc. of the 38th Annual Congress of Nigerian Vetnary Medical Assosiation. Badagry.

Yacob, H.T., Yalew, T.A. and Dinka, A.A. (2008). Ectoparasite prevalence in sheep and in goats in and around Wolaita Soddo, Suothern Ethiopia. Revue. Med. Vet., 159 (8\&9): 450-454 